\title{
PRELIMINARY EXPERIENCE FROM THE T-SAT PROJECT
}

\author{
Witold Kinsner ${ }^{1}$, M. D. (Ron) Britton ${ }^{2}$, Dario Schor ${ }^{1}$, Arash Fazel Darbandi ${ }^{1}$, \\ Kris Goodmanson ${ }^{3}$, Cody Friesen ${ }^{4}$, Emily Bashford ${ }^{5}$ \\ ${ }^{1}$ Dept. of Electrical \& Computer Engineering, ${ }^{3}$ Dept. of Mechanical Engineering, ${ }^{2}$ Faculty of Engineering \\ ${ }^{4}$ Dept. of Physics \& Astronomy, Faculty of Science, \\ ${ }^{5}$ Dept. of Marketing \& Management of Organizations, Asper Business School \\ University of Manitoba, Winnipeg, MB, Canada, R3T 5V6 \\ \{kinsner|dschor|arash\}@ece.umanitoba.ca, \{britton|umgood24|umfri347|umbashfe\}@cc.umanitoba.ca
}

\begin{abstract}
The design of complex systems requires input from many disciplines including science, engineering technology, business, and law. Students from a single department are seldom exposed to interdisciplinary projects through classroom activities. Such multi-facet experience is obtained through extracurricular activities and design competitions. The Canadian Satellite Design Challenge was recently introduced to design, build, test, and launch an operational small satellite. The University of Manitoba has a team of 79 undergraduate and graduate students from several faculties, working together to design a triple pico-satellite (T-Sat).

This paper presents some of the lessons learned from the first phase of the T-Sat project and insight into some of the benefits of interdisciplinary, complex projects on engineering education.
\end{abstract}

Keywords: Multidisciplinary design; collaborative design; complex system design; aerospace applications; academic/industry/government partnership.

\section{INTRODUCTION}

Design and implementation of complex systems is a process involving science, engineering, technology, business, law, and other disciplines. Students from a single department in a given faculty are often exposed to the educational scope of that department only. In order to expand the scope of their learning, many universities and organizations have promoted undergraduate engineering design competitions, such as the Society for Automotive Engineers (SAE) Solar Car or Formula-SAE or Super Mileage competitions, and NASAs Space Elevator competition. For similar reasons, the Canadian Satellite Design Challenge (CSDC) was recently introduced to design, build, test and launch an operational small (nano or triple pico) satellite. The University of Manitoba (UofM) has a team of about 79 undergraduate and graduate students from several faculties, working together in several groups on such a satellite called T-Sat.
The specifications [Geoc09, Geoc11a, Geoc11b] require that the satellite include at least one science instrument for observations of the Earth environment, the near-Earth space environment, or deep-space objects, with emphasis on the Earths surface (remote sensing), the atmosphere, the ionosphere, the magnetosphere, solar astronomy, or stellar astronomy for potential use in research and teaching. The satellite will use mostly commercially-available off-the-shelf components, will undergo full space environmental and launch qualification testing, and the winning satellite(s) will be selected to be launched into orbit. The project has several extensions of the SAE model, including (a) the Prime Contractor of a satellite mission, and a CSDC Managing Body acting as the customer, and (b) a complete course on spacecraft design.

The University of Manitoba Space Applications and Technology Society (UMSATS) has recently been formed to manage and oversee the T-Sat project [UMSA11]. The society consists of a student-run executive committee and a number of teams responsible for various aspects pertaining to the satellite mission. In addition, the university advisors have setup a strong infrastructure to support the students that includes academic advisors, aerospace advisors, industry advisors, and government advisors [ScFK11]. The University of Manitoba also provide other elements in support of the T-Sat project infrastructure. For example, a satellite ground station that will be used as a part of Global Educational Network for Satellite Operations (GENSO) to obtain data from the satellite. This paper presents some of the lessons learned by the UMSATS team from the first phase of the project.

\section{T-SAT MISSION OVERVIEW}

The T-Sat mission consists of the design and implementation of a satellite and scientific experiments, the managerial and organizational components of the mission, and the outreach components [ScFK11].

The T-Sat mission aims to perform two experiments to study life in space and the Earth's environment through re- 
mote sensing. The life-science experiment tests the survivability of Tardigrades (a class of extremophiles organisms) to the very hostile environment with extreme cold, heat, pressure, and radiation. These organisms survive these extremes by essentially shutting off their biochemistry and entering a suspended state. The mission is to send a colony of Tardigrades into low-earth-orbit in a suspended state, expose them to the harsh space environment, and then attempt to revive them while in orbit. If successful, this will broaden the range of conditions for which we currently consider it possible for life to exist and provide valuable information about life under extreme stresses.

The remote sensing experiment aims to study our planet's complex ecosystem. Since, such remote sensing experiments are conducted using very large and expensive satellite missions, the use of small satellites could help in promoting the newly proposed architecture that uses constellations of small satellites to replace single large units [PeOM04, PeTK04 PBTD08, Schi06, Schi09a, Schi09b, KTPT99]. The specific remote sensing experiment gathers spectrographic data from the Sun and the upper atmosphere of the Earth amounting to measuring the intensity of light over a broad range of frequencies. This data can be matched to theoretical models in order to better understand the Sun, and by observing the wavelengths of light absorbed or scattered at high altitudes, one can measure the molecular composition of the Earth's upper atmosphere. This kind of data is very important for modelling a wide variety of environmental phenomena and identifying areas rich in natural resources.

\section{TEAM STRUCTURE}

The University of Manitoba Space Application and Technology Society (UMSATS) is made up of 79 undergraduate and graduate students working together on the design, implementation, fundraising, and promotion of T-Sat satellite mission. The students bring a variety of complementary skills to the project from engineering, science, business, school of art, and the first year university program as shown by Table 1.

\subsection{Internal Team Structure}

\subsubsection{Executive Committee}

The society is managed by an elected executive committee shown in Fig. 1. The executive consists of a Project Leader (responsible for managing and coordinating the team), Business Coordinators (overseeing the three business teams: Outreach, Finance, and Professional Relations), Mechanical Coordinator (overseeing the Structure, Thermal, and Attitude Determination \& Control teams), Electrical and Computer Technical Coordinators (overseeing the Communications, Power, and Command \& Data Handling teams), Payload Coordinators (overseeing the Design, Integration of Payloads with the Satellite Bus teams), and Secretaries/Document Managers
Table 1: UMSATS members by department (as of May 2/11)

\begin{tabular}{|llc|}
\hline Faculty & Department & Students \\
\hline \hline $\begin{array}{l}\text { Asper School of } \\
\text { Business }\end{array}$ & Accounting & 1 \\
\hline $\begin{array}{l}\text { Asper School of } \\
\text { Business }\end{array}$ & $\begin{array}{l}\text { Actuarial } \\
\text { Mathematics }\end{array}$ & 2 \\
\hline $\begin{array}{l}\text { Asper School of } \\
\text { Business }\end{array}$ & Marketing & 3 \\
\hline $\begin{array}{l}\text { Faculty of } \\
\text { Engineering }\end{array}$ & Biosystems Eng. & 1 \\
\hline $\begin{array}{l}\text { Faculty of } \\
\text { Engineering }\end{array}$ & Civil Eng. & 2 \\
\hline $\begin{array}{l}\text { Faculty of } \\
\text { Engineering }\end{array}$ & Electrical \& \\
\hline $\begin{array}{l}\text { Faculty of } \\
\text { Engineering }\end{array}$ & Mechanical Eng. & 33 \\
\hline $\begin{array}{l}\text { Faculty of Graduate } \\
\text { Studies }\end{array}$ & $\begin{array}{l}\text { Electrical \& } \\
\text { Computer Eng. }\end{array}$ & 13 \\
\hline $\begin{array}{l}\text { Faculty of Graduate } \\
\text { Studies }\end{array}$ & Mechanical Eng. \\
\hline Faculty of Science & Astronomy & 1 \\
\hline Faculty of Science & Computer Science & 1 \\
\hline Faculty of Science & Biochemistry & 1 \\
\hline Faculty of Science & Chemistry & 1 \\
\hline Faculty of Science & Mathematics & 1 \\
\hline Faculty of Science & Physics & 1 \\
\hline School of Art & Graphic Design \\
\hline University 1 & University 1 & 1 \\
\hline & & 1 \\
\hline
\end{tabular}

[UMSA11, ScFK11]. There is a number of other positions to address the needs of the team that include leads for various design elements, webmaster, and photographer.

\subsubsection{UMSATS Teams}

UMSATS is currently divided into 7 teams with plans for additional teams to be developed at later stages of the T-Sat mission. The following sections describe each of the seven teams and their responsibilities [ScFK11].

\section{Business Team}

The Business Team is primarily responsible for the finances and promotional aspects of the project.

Payload

The payload team is responsible for the scientific experiments for the T-Sat mission. While on-orbit, this team is responsible for analyzing and interpreting the data received from the spacecraft.

Attitude Determination \& Control Systems Team

The Attitude Determination \& Control Systems Team is responsible for controlling the orientation of the satellite in space as required by the on-board scientific experiments. 


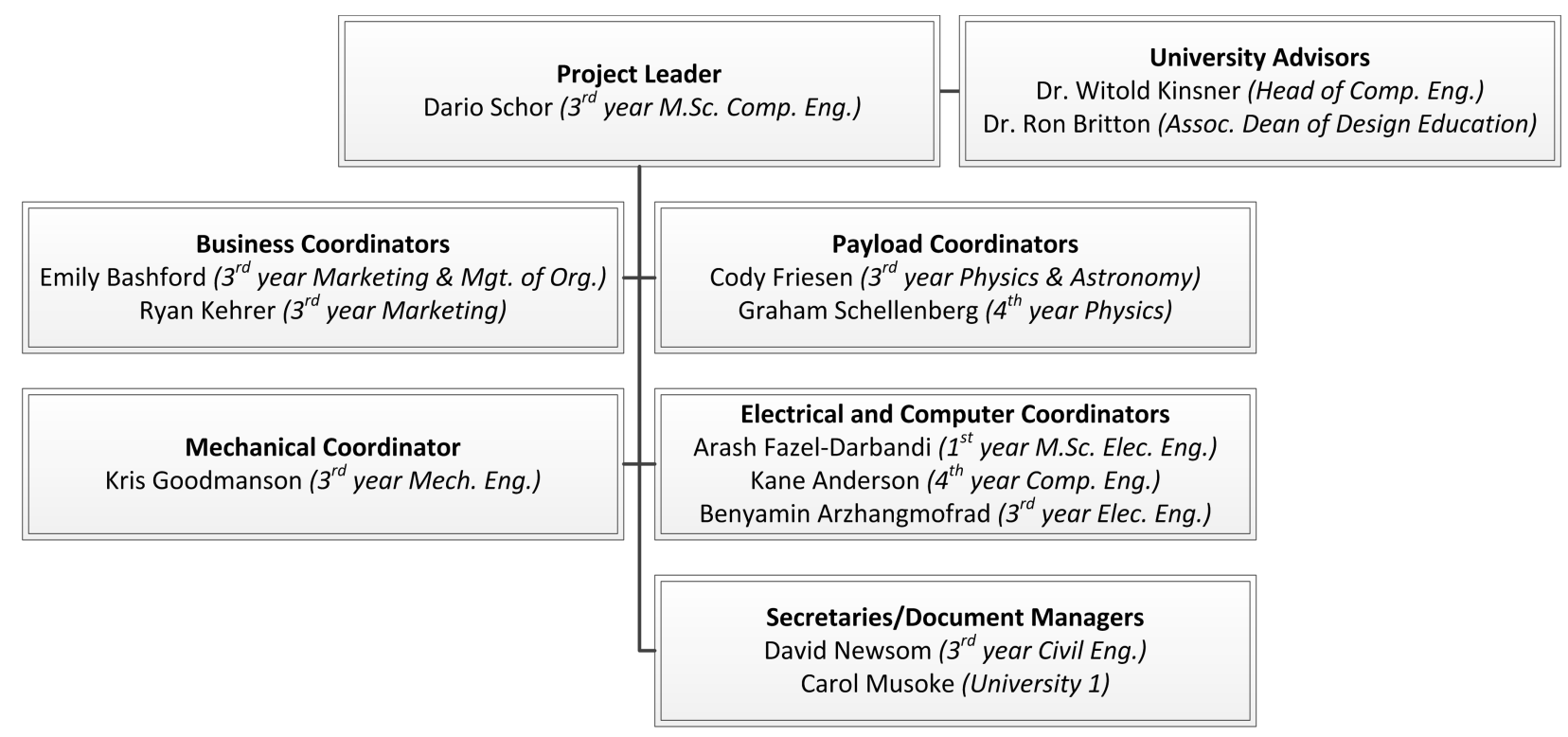

Fig. 1: UMSATS executive organization structure showing the critical teams.

\section{Communications Team}

The Communications Team is responsible for the communication system needed to send payload data to the ground and receive commands from the ground station using Amateur Radio bands.

\section{Command \& Data Handling Team}

The Command \& Data Handling Team is responsible for the flight computer hardware and software.

\section{Power Systems Team}

The Power Systems Team is responsible for implementing an efficient energy source for the satellite using solar panels to charge batteries to drive the mission.

\section{Structure \& Thermal Team}

The Structure \& Thermal Team is responsible for the mechanical properties of the satellite during launch and while in orbit including the frame and heat distribution.

\subsection{External Team Structure}

There are a number of external stakeholders that form the necessary support structure for the T-Sat mission. The stakeholders are composed of eight groups: (i) External Advisors, (ii) Outreach audiences, (iii) the CSDC Management Team, (iv) Observers, (v) Researchers, (vi) Funding sources, (vii) Suppliers, and (viii) Media sources [ScFK11]. These groups and its major members are shown in Fig. 2. Overall, these groups provide many opportunities to interact with industry and gain practical experience.

\section{External Advisors}

The 43 External Advisors are experts that review documents and designs during each phase of the project to identify ways to improve the spacecraft and activities pertaining to the T-Sat mission. This large group is made up of (i) academic advisors helping engineering and scientific matters, as well as in the day-to-day operations of the mission, (ii) aerospace professionals providing invaluable feedback on the designs based on many years of experience in the field, (iii) industry professionals (other than aerospace directly) serving as mentors for the design, implementation, and project management components of the mission, (iv) military representatives providing another perspective on the logistics of design and much experience in orbit dynamics, and (v) the amateur radio advisors assisting the Communications Team in the designs as well as the operation, testing of the ground station.

\section{Outreach}

The outreach stakeholders are all the institutions and organizations that invite UMSATS to give presentations on the T-Sat mission. The group consists of students at various levels and special interest groups (i.e., IEEE Winnipeg Section). In addition, the outreach stakeholders include many interactions through special events such as the Manitoba Space Adventure Camp.

\section{Consumer}

The CSDC Management Team is the only consumer for the team. They set the requirements for the mission and evaluate the spacecraft to ensure it meets the competition 


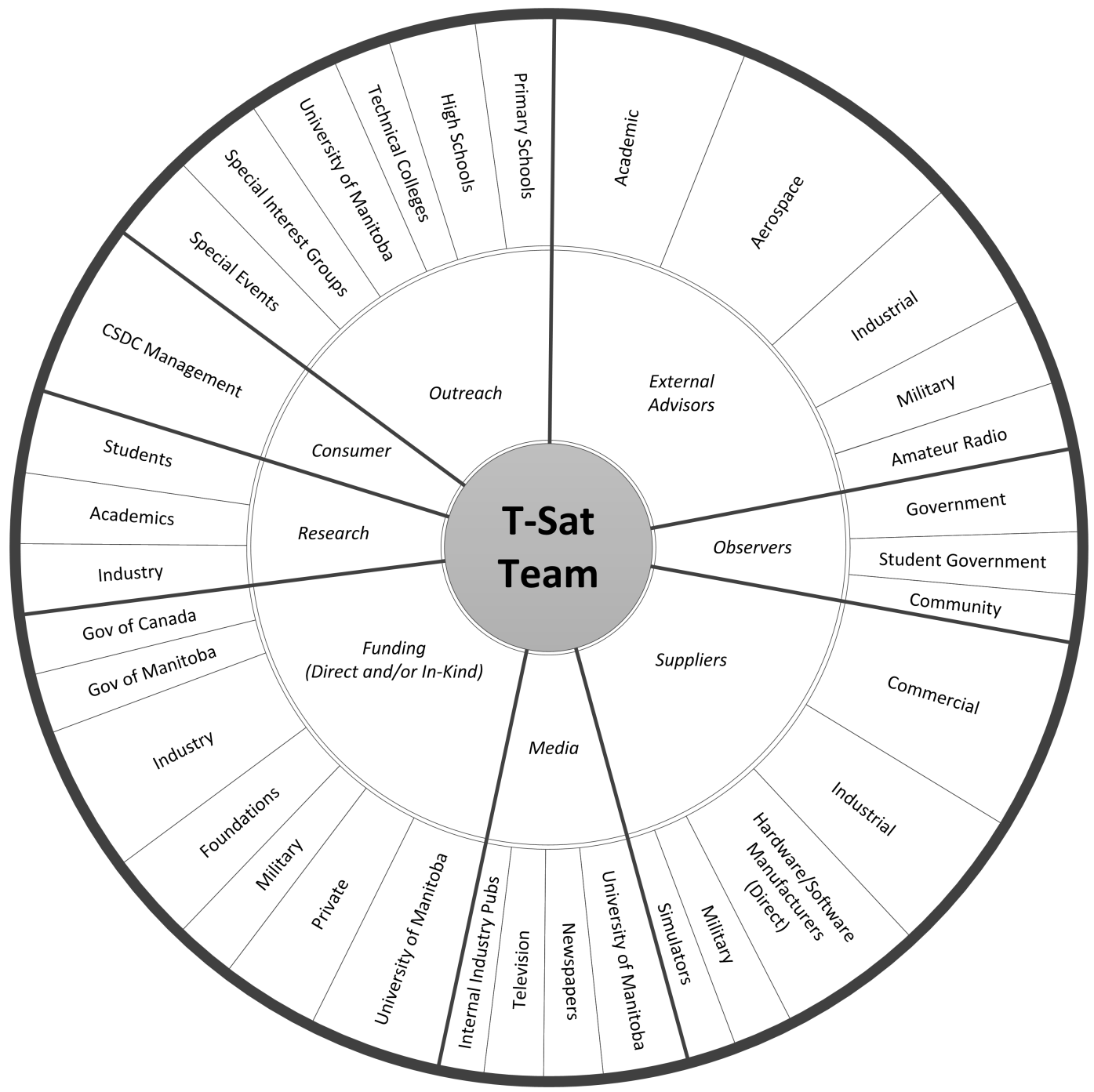

Fig. 2: External T-Sat stakeholders [ScFK11].

standards.

\section{Research}

The researchers involved in the mission aim to study the scientific data obtained from the two experiments running on-board the satellite.

\section{Observers}

The five observers are key individuals in the community that help spread information about UMSATS activities, and also help obtaining many of the resources needed for the mission.

\section{Funding}

The funding sources (direct and/or in-kind) help procure the resources required for the T-Sat mission.
Suppliers

The suppliers provide all the hardware and software required to design, implement, and test the spacecraft's operation.

\section{Media}

The media helps promote the activities of UMSATS to the community at large.

\section{LEARNING OUTSIDE THE CLASSROOM}

Based on the brief description of the team, the T-Sat project offers students many opportunities to apply the knowledge gained through their formal education at the University of Manitoba and also expand that knowledge with practical implementations in a complex project, interdisciplinary work, communication, and project management tasks. 


\subsection{Complex System Design}

The T-Sat project offers a venue for a complex system design that contributes to the formation of engineering and science graduates who have to research, design, redesign, prototype, analyze, implement, verify and test components for the mission. The programs at the university offer many of the fundamental and background information needed by students to design components, and it is up to them to expand on these ideas and design functional components for the satellite. For instance, although the University of Manitoba does not offer courses on orbit dynamics, all science and engineering students have sufficient mathematics and physics background required to understand the concepts, which combined with research and communications with external advisors, the team can confidently design and implement an orbit determination and control system for the mission. The business and arts students have also been gaining technical knowledge as they need to understand the major decisions from the team and their overall designs in order to convey the ideas to industry and other groups to request funding.

In addition, there are many lessons in the design of complex systems go beyond the classroom experience. That is because design problems in assignments or laboratories are conceptual and require students to make reasonable assumptions for how the components interact or behave within a larger system. Since such complex projects are rarely implemented in a classroom environment, the students never get to test their assumptions or get feedback from others as to whether those assumptions are indeed accurate for the real system. In T-Sat, there are very few parameters offered by the competition, so most of the initial assumptions and estimates for the designs are developed by students. This requires excellent communication and teamwork in order to understand what is required from other teams and, at the same time, request necessary information from other teams.

\subsection{Team Communication}

As simple as communicating and working with other teams sounds, during the initial meetings, the design interdependencies caused some anxiety among team members that were unable to complete tasks because they required information from other groups, who were in turn waiting for information from other groups and so on. A typical gridlock. In order to resolve this gridlock, the technical coordinators encouraged students to estimate some of their initial calculations based on information from other university satellites, common sense, and simulations. As the estimates were shared within UMSATS, the teams were able to complete their first round of high level designs and move on to refine the estimates incorporating information from other groups. This process is expected to continue as the estimates converge towards the actual parameters for the mission.

\subsection{Business Acumen}

From a business perspective, this is just like starting a new company. One must research the industry, competition, and many other aspects in order to get an understanding of how to approach the problem. The team uses regular brainstorming meetings to come up with creative and innovative ways to promote the project to industry, young people, and the community at large. The different audiences pose many challenges for the team, so before each presentation, representatives from UMSATS discuss the terminology and depth that would best suit the audience. This is a valuable skill that requires lots of effort and collaboration from many members of the team in order to decide how to best present the material to convey complex messages to young audiences and describe designs to industry.

\subsection{Internal and External Teaching}

Teaching is another important element that is tightly linked to the project at many levels. The team has organized a series of workshops on Matlab, Simulink, PS-CAD, embedded systems, and are planning an orbit dynamics workshop for the summer months. These are opened to the entire university and serve to promote the project as well as give the older students chances to practice their teaching skills by preparing materials and exercises for the workshops. In addition, there is extensive informal student-to-student teaching both within a specific discipline and interdisciplinary as many students are interested in a variety of topics and use this opportunity to learn about other fields. In those cases where senior students are also stumped by a question, the external advisors provide guidance and ideas for experiments to allow students to learn independently and develop an intuition on many of the technical issues being addressed by T-Sat.

\subsection{Outreach}

Furthermore, the University of Manitoba has purposely structured the project to foster the life-long independent learning of first year students. The team and the advisors actively recruited 16 first year students knowing that they may not be able to contribute as much in the early stages, but that they would gain valuable experience from their peers by being involved in the project. The team embraces this philosophy by establishing a comfortable learning environment that encourages everyone to ask questions and participate in the discussions. Naturally, some of the senior students play the role of the teacher and answer questions from the group and assign tasks appropriate to each members level of experience. In the long run, as the older students graduate, the new generation of UMSATS leaders will be ready to take over and continue working on the mission without much of a learning curve. 


\section{CONCLUDING REMARKS}

In terms of complexity, this T-Sat project exceeds many other complex projects tried at the University of Manitoba. The experience so far is extraordinary in terms of understanding complex systems, team communication, business acumen, internal and external teaching, and outreach.

The next few months will put many of the team's ideas to the test as the students will begin the developing detailed designs, prototypes, and fundraising for the project. However, the preliminary reviews of the T-Sat project look very promising as it provides practical experience for students of all disciplines, encourages team work and communication skills, and make for a very unique learning environment.

\section{Acknowledgments}

Special thanks go to the 79 students working on UMSATS and the 48 external advisors and observers for contributing to this unique experience. This work is supported in part by the Faculty of Engineering, Faculty of Science, Asper School of Business, School of Art, Manitoba Aerospace, Manitoba aerospace industries, and the Government of Manitoba through MindSet.

\section{References}

[Geoc09] Geocentrix Technologies Ltd., H.R. MacMillan Space Centre, and Dr. Jaymie M. Matthews, "A proposal to initiate a satellite design challenge for canadian universities," Vancouver, BC: Geocentrix, January 13, 2009.

[Geoc11a] Geocentrix Technologies Ltd., "CSDC Rules and Regulations: Mission-level requirement document," Vancouver, BC: Geocentrix, January, 2011.

[Geoc11b] Geocentrix Technologies Ltd., "CSDC Rules and Requirements," Vancouver, BC: Geocentrix, January, 2011.
[KTPT99] Christopher Kitts, Robert Twiggs, Freddy Pranajaya, Julie Townsend, and Bryan Palmintier, "Experiments in distributed microsatellite space systems," American Institute of Aeronautics and Astronautics, AIAA-99-4654, 1999, 10 pp. Available as of May 2011 from AMSAT http://www.amsat.org.ar/lu7eim/SSDL9914.pdf.

[PBTD08] Carlo Pinciroli, Mauro Birattari, Elio Tuci, Marco Dorigo, Marco del Rey Zapatero, Tamas Vinko, and Dario Izzo, "Self-organizing and scalable shape formation for a swarm of pico satellites," in Proc 2008 NASA/ESA Conference on Adaptive Hardware and Systems, AHS 2008; (Noordwijk, The Netherlands; 22-25 June 2008), pp. 57-61, 2008 \{ISBN: 978-0-7695-3166-3\}.

[PeOM04] Joseph N. Pelton, Robert J. Oslund, and Peter Marshall (eds.), Communications Satellites: Global Change Agents. Mahwah, NJ: Lawrence Erlbaim Associates, 2004 \{ISBN 0-8058-4961-0\}.

[PeTK04] Joseph N. Pelton, Takashi Iida, and Naoto Kadowaki, "The Future of satellite communications systems," in [PeOM04; Ch. 14].

[ScFK11] Dario Schor, Arash Fazel-Darbandi, and Witold Kinsner, TSat Project Management Plan, Tech. Rep. 2.4. Winnipeg, MB: University of Manitoba Space Applications and Technology Society (UMSATS), May 2, 2011, 71pp.

[Schi06] K. Schilling, "Design of pico-satellites for education in systems engineering," Aerospace and Electronic Systems Magazine, vol. 21, no. 7, pp. 9-14, July 2006.

[Schi09a] Klaus Schilling, "Earth observation by distributed networks of small satellites," in 2009 International Conference on Instrumentation, Communications, Information Technology, and Biomedical Engineering (ICICI-BME) (Bandung, Indonesia; 23-25 Nov. 2009), pp. 1-3, 2009 \{ISBN 978-14244-4999-6\}.

[Schi09b] K. Schilling, "Networked distributed pico-satellite systems for Earth observation and telecommunication applications," Flying, 2009. Available as of May 2011 from http://lib.physcon.ru/download/p1874.pdf.

[UMSA11] University of Manitoba Space Applications and Technology Society, "UMSATS Constitution,", Winnipeg, MB: University of Manitoba, February 2, 2011. 